\title{
Gas analysis of exhumed cadavers buried for 30 years: a case report about long time alteration
}

\author{
V. Varlet • C. Bruguier • S. Grabherr • M. Augsburger • \\ P. Mangin • T. Uldin
}

Received: 18 September 2013 / Accepted: 16 April 2014 / Published online: 3 May 2014

(C) Springer-Verlag Berlin Heidelberg 2014

\begin{abstract}
Due to important alteration caused by long time decomposition, the gases in human bodies buried for more than a year have not been investigated. For the first time, the results of gas analysis sampled from bodies recently exhumed after 30 years are presented. Adipocere formation has prevented the bodies from too important alteration, and gaseous areas were identified. The sampling was performed with airtight syringes assisted by multi-detector computed tomography (MDCT) in those specific areas. The important amount of methane $\left(\mathrm{CH}_{4}\right)$, coupled to weak amounts of hydrogen $\left(\mathrm{H}_{2}\right)$ and carbon dioxide $\left(\mathrm{CO}_{2}\right)$, usual gaseous alteration indicators, have permitted to confirm methanogenesis mechanism for long period of alteration. $\mathrm{H}_{2}$ and $\mathrm{CO}_{2}$ produced during the first stages of the alteration process were consumed through anaerobic oxidation by methanogenic bacteria, generating $\mathrm{CH}_{4}$.
\end{abstract}

Keywords Alteration · Gas analysis · HS-GC-MS/TCD • MDCT

\footnotetext{
V. Varlet $(\bowtie) \cdot$ M. Augsburger $\cdot$ P. Mangin

Forensic Chemistry and Toxicology Unit, University Center of Legal

Medicine Lausanne-Geneva, Bugnon 21, 1011 Lausanne,

Switzerland

e-mail: vincent.varlet@chuv.ch

C. Bruguier $\cdot$ S. Grabherr

Forensic Imaging Unit, University Center of Legal Medicine

Lausanne-Geneva, Bugnon 21, 1011 Lausanne, Switzerland

C. Bruguier

Department of Diagnostic and Interventional Radiology, University

Hospital of Lausanne, Bugnon 46, 1011 Lausanne, Switzerland

P. Mangin $\cdot$ T. Uldin

University Center of Legal Medicine Lausanne-Geneva, University

of Geneva, 1211 Geneva, Switzerland
}

\section{Introduction}

Gas analysis is a very complex investigation in analytical chemistry. The most challenging task concerns the sampling step, because of leaks that need to be avoided. Today, sampling strategies have been developed to fulfil this drawback [1-6]. However, postmortem alteration gas investigation presents another difficulty. Several studies showed that multidetector computed tomography (MDCT) is helpful to detect gas presence in bodies [7-9]. However, depending on the time and environmental conditions of alteration, the body can be differently altered and a decompartmentalization can lead to an open system whose gas composition is similar to ambient air. This may be the main reason why the gaseous composition of bodies with an alteration time of more than several weeks has not been reported yet.

The aim of this case report is to validate the hypothesis of $\mathrm{CH}_{4}$ generation during human body alteration. After 30 years of burial, high amounts of $\mathrm{CH}_{4}(>10 \%)$ are expected, generated by methanogenic bacteria from anaerobic oxidation of $\mathrm{H}_{2}$ with $\mathrm{CO}_{2}$. Therefore, weak percentages of $\mathrm{H}_{2}$ and $\mathrm{CO}_{2}$ could be also expected. To our knowledge, gaseous compositions from 30 years buried bodies are reported for the first time.

\section{Case history}

Twelve bodies buried in the mid-1980s of the last century have been recently exhumed for the reaffectation of a cemetery. Because of the soil quality in the burial ground (clay soil), the bodies underwent a specific alteration. Indeed, due to oxygen deficiency conditions, most of decomposers (bacteria, fungi and scavengers) could not alter the bodies as in usual conditions. Then, after the autolysis, oxygen present in the body is quickly depleted by the aerobic organisms which creates an optimal environment for the growth of anaerobic 
organisms. However, due to the very stable burial conditions (cold temperature) and specific moisture, most of the exhumed bodies showed good preservation and adipocere. The bodies were partially very well preserved because the decomposition has not reached the main alteration stage.

\section{Materials and methods}

\section{Subjects}

Two bodies (SZ 13006 and SZ 13004) among the twelve exhumed ones (cemetery of Einsiedeln, canton of Schwyz, Switzerland) underwent a full CT scan examination following an autopsy (Fig. 1). Decomposition has led to an alteration of organs and tissues but relative airtight gaseous volumes can be clearly identified, well protected by adipoceres. SZ 13004 body was stored in a sealed zinc coffin, embalmed and wrapped into a shroud (deceased probably abroad) and buried in a dense clay soil. The body was exhumed on June 5th, 2013, wrapped into a plastic sheet, stored under soil at the cemetery until June 27th, 2013 when the body was transported to CURML (University Center of Legal Medicine, Lausanne, Switzerland) and autopsied the same day.

SZ_13006 body was preserved in a wooden coffin in dense clay soil, and the body was covered by a kind of plastic sheet which was an inlay of the coffin. The body was exhumed on June 5th, 2013, wrapped into a plastic sheet, stored under soil at the cemetery until June 27th, 2013 when the body was transported to CURML (University Center of Legal Medicine, Lausanne, Switzerland) and autopsied on July 2nd, 2013.

\section{Collection of gas samples from the bodies}

Gas sampling was performed under MDCT guiding following a standardized protocol recently developed in our centre [6]. Gas sampling is the critical step in this work. The sampling protocol must guarantee the absence of leaks from the bodies,
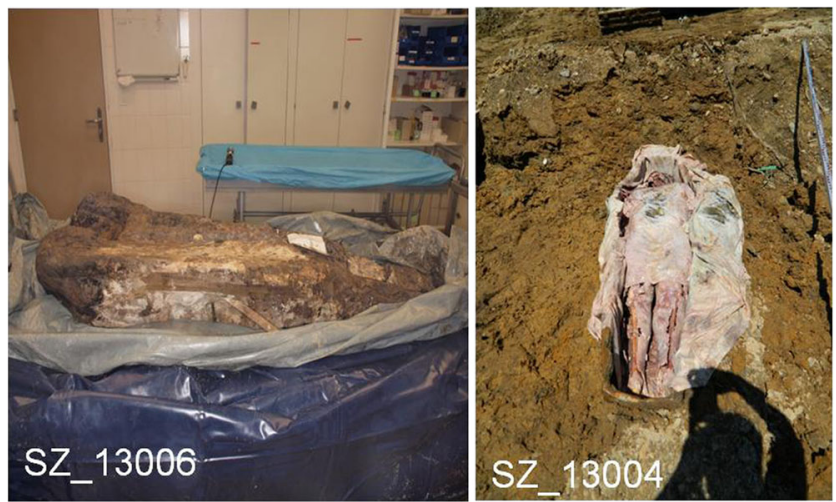

Fig. 1 Photos of the two cadavers analysed in the study with gas compositions in Figs. 3 and 4, respectively and the sampling material must guarantee the absence of air contamination in the bodies and/or gas sampled (Fig. 2). Gas bubbles were detected by multi-detector computed tomography (MDCT) on a native CT scan [10]. Using the biopsy mode which corresponds to a radiological guidance, it was possible to target the aeric region to be punctured. A three-way tap in closed position is mounted on a needle and introduced through the body thanks to three-dimensional coordinates. A second CT scan is performed to check the position of the needles in the body. Luer-lock PTFE syringes were then mounted on the tap which was slowly opened. Therefore, gas volumes were sampled from the sampling sites of interest. The three-way taps were closed, and the system (syringe + tap + needle) was removed from the body. The gas samples were then individually transferred in headspace vial. These vials were preliminary filled with stabilized water (Millipore) heated during $3 \mathrm{~h}$ at $60{ }^{\circ} \mathrm{C}$, then kept in fridge until use. Two needles were installed through the septum: the needle of the system (syringe + tap + needle) and another simple needle. The transferred gas takes the place of the water which can be evacuated through the second inserted needle. A residual water quantity must be left to permit a complete airtightness. Vials were stored upside down in fridge until analyses. Preliminary studies have already been led and have concluded for sample stability over at least 2 months.

\section{Reagents}

All the analytical gases used were from Carbagas (Lausanne, Switzerland): certified $\mathrm{CO}_{2}$ (purity of $99.998 \%$ ) and certified methane (99.995\% purity). Atmospheric air was used as source of $\mathrm{O}_{2}$ and $\mathrm{N}_{2}$.

\section{GC-TCD/MS analysis}

An Agilent 6890N GC (Agilent Technologies, Palo Alto, CA) combined with a headspace gas autosampler and equipped with an Agilent select permanent gases column arrangement was used. This column arrangement is specially designed for gas analysis and contains two capillary columns in parallel: a molecular sieve $5 \AA$ PLOT capillary column $(10 \mathrm{~m} \times 0.32 \mathrm{~mm}$ i.d.) and a Porabond Q (50 $\mathrm{m} \times 0.53 \mathrm{~mm}$ i.d.), allowing the separation of carbon dioxide. The end of the capillary column was installed on a three-way valve mounted into the gas chromatograph. This valve enables the analytes to be directed, by a manual commutation, to a thermal conductivity detector (TCD) or to an Agilent 5973 mass spectrometer (MS) (Agilent Technologies, Palo Alto, CA). The temperature was set to an isothermal $\left(45^{\circ} \mathrm{C}\right)$ held for $8 \mathrm{~min}$, and the injector (splitless mode) was set at $100{ }^{\circ} \mathrm{C}$. Helium was employed as the carrier gas $\left(8 \mathrm{ml} \mathrm{min}{ }^{-1}\right.$, constant flow). The gas identification was performed by the injection of gas standards and mass spectra. The MS was operating in the electron ionization (EI) mode at 

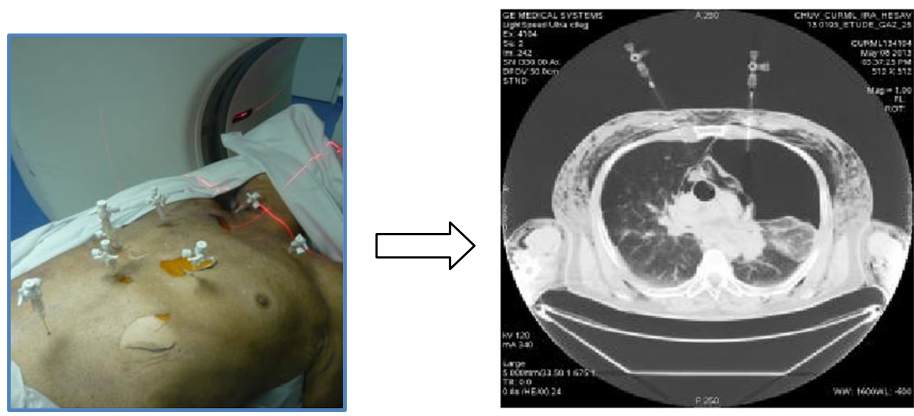

b.Needles positions checking CT scan

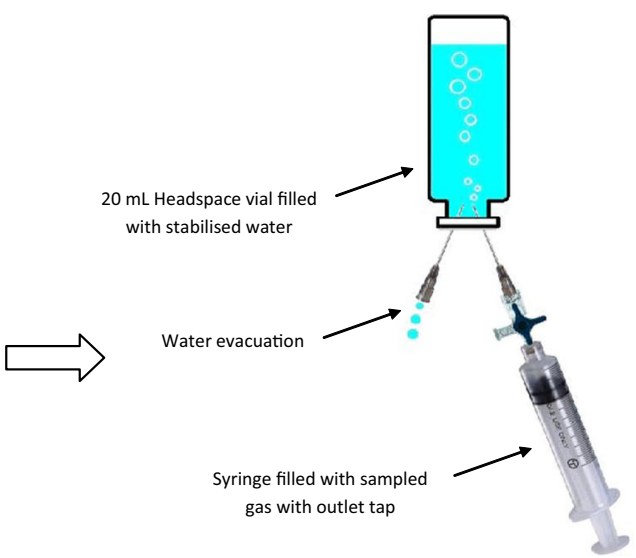

c.Gases transfer in Headspace vials

Fig. 2 Gas sampling protocol of alteration gases. a Installation of needles and outlet taps in the sampling site of interest, b CT-guided biopsy and c experimental setup for filling HS vials with gases from biological matrices - illustrative photos and CT scan only and not cases included in the study

$70 \mathrm{eV}$ with an ion source temperature of $230^{\circ} \mathrm{C}$. The analyser temperature was set at $150^{\circ} \mathrm{C}$ and the interface MS temperature at $250^{\circ} \mathrm{C}$. Acquisition of signals was in full scan mode (2-100 amu). The gas quantification was performed with the TCD at $150{ }^{\circ} \mathrm{C}$, prior calibrated for each gas with standard gases. The use of TCD was mandatory to put in evidence the eventual presence of $\mathrm{H}_{2}$. With this capillary column system, all the gases could be detected in the same run. As the TCD $\mathrm{H}_{2}$ calibration is complex, the amount of $\mathrm{H} 2$ in the gas mixture was calculated to be the difference between the sum of all the other components up to $100 \%[11,12]$.

\section{Scan parameters}

Non-enhanced MDCT scans were carried out after the reception of the bodies using an eight-row MDCT unit (CT LightSpeed 8; GE HealthCare, Milwaukee, WI, USA) with the following scan parameters: scan field of view (large) and display field of view, $50 \mathrm{~cm}$; slice-thickness, $1.25 \mathrm{~mm}$; $120 \mathrm{KV} ; 100-350 \mathrm{~mA}$ (modulated); rotation tube, $1 \mathrm{~s}$. Standard and bone filter reconstructions were acquired.

\section{Results and discussion}

The main part of publications in legal medicine done on gas analysis concerns the possibility to distinguish alteration gases from vital embolism. Studies have been performed on rabbits [13-15], rats [15] and cetaceans [16]. Generally, the alteration time did not overcome 4 weeks. Alteration is diagnosed if hydrogen $\left(\mathrm{H}_{2}\right)$, methane $\left(\mathrm{CH}_{4}\right)$ or hydrogen sulphide $\left(\mathrm{H}_{2} \mathrm{~S}\right)$ is detected. Moreover, with this kind of alteration time, oxygen $\left(\mathrm{O}_{2}\right)$ concentration, although variable, should not overcome $10 \%$, nitrogen $\left(\mathrm{N}_{2}\right)$ concentration should be lower than $70 \%$, carbon dioxide $\left(\mathrm{CO}_{2}\right)$ should be higher than $15 \%$ and the ratio
$\mathrm{CO}_{2} / \mathrm{N}_{2}$ should be higher than 0.2 [17]. It is preferable to sample gas in areas independent from the endogenous formation of gases such as stomach or intestines because the origin of $\mathrm{CH}_{4}$ or $\mathrm{H}_{2}$ could be difficult to identify (endogenous generation vs. alteration). In these cases, as the microflora and the food of rabbits, rats or cetaceans are really different from this of human, an extrapolation of these works to human postmortem physiology is not relevant. However, results obtained in heart cavities provide useful information to understand human body alteration.

Presence of methane and hydrogen in the rabbit's intestines and heart was found random and did not seem to have any relationships to postmortem time or decomposition $(67 \mathrm{~h}$ of postmortem delay, heart gas composition about $30 \%$ of $\mathrm{CO}_{2}$, $30 \%$ of $\mathrm{N}_{2}, 30 \%$ of $\mathrm{H}_{2}, 8 \%$ of $\mathrm{O}_{2}$ and $2 \%$ of $\mathrm{CH}_{4}$ ) [14]. Twenty days after death, the gas composition in rabbit abdominal cavity (similar to this in rabbit stomach containing some food and left at $15{ }^{\circ} \mathrm{C}$ ) approximated $50 \%$ of $\mathrm{CO}_{2}, 15 \%$ of $\mathrm{N}_{2}$ and $35 \%$ of $\mathrm{H}_{2}$, and $\mathrm{CH}_{4}$ was not reported [15]. In other studies also performed on rabbits, 13 days after death, the cardiac gas composition was about $20 \%$ of $\mathrm{CO}_{2}, 20 \%$ of $\mathrm{N}_{2}, 50 \%$ of $\mathrm{H}_{2}, 2 \%$ of $\mathrm{O}_{2}$ and $8 \%$ of $\mathrm{CH}_{4}$, and the abdominal gas composition was about $47 \%$ of $\mathrm{CO}_{2}, 7 \%$ of $\mathrm{N}_{2}, 30 \%$ of $\mathrm{H}_{2}, 1.5 \%$ of $\mathrm{O}_{2}$ and $14.5 \%$ of $\mathrm{CH}_{4}$. Environmental temperature, food, sampling sites and sampling protocols can easily explain those differences.

Concerning gas composition in altered human bodies, only few data are available. Gas composition in decomposing bodies have been reported close to 23 to $46 \%$ of $\mathrm{N}_{2}, 5$ to $8 \%$ of $\mathrm{O}_{2}, 3$ to $45 \%$ of $\mathrm{CO}_{2}$ and 14 to $27 \%$ of $\mathrm{H}_{2}$, without any information concerning the postmortem delay or sampling sites [18]. In one case, $\mathrm{CH}_{4}$ was detected (0.1\%). Several other cases were reported in Germany. The cardiac gas composition was close to, after 1 week of alteration, $30 \%$ of $\mathrm{CO}_{2}, 30 \%$ of $\mathrm{N}_{2}, 30 \%$ of $\mathrm{H}_{2},<5 \%$ of $\mathrm{O}_{2}$ and $<5 \%$ of $\mathrm{CH}_{4}$; after 2 weeks of alteration, $50 \%$ of $\mathrm{CO}_{2}, 20 \%$ of $\mathrm{N}_{2}, 25 \%$ of 
Fig. 3 CT scan images and gas composition of the right flank and pelvic minor cavities from a 30-year buried human body (sampling needles in the white circles on CT scan images; $I B$ iliac bone, $F H$ femoral head). a Right flank. b Pelvis minor cavity
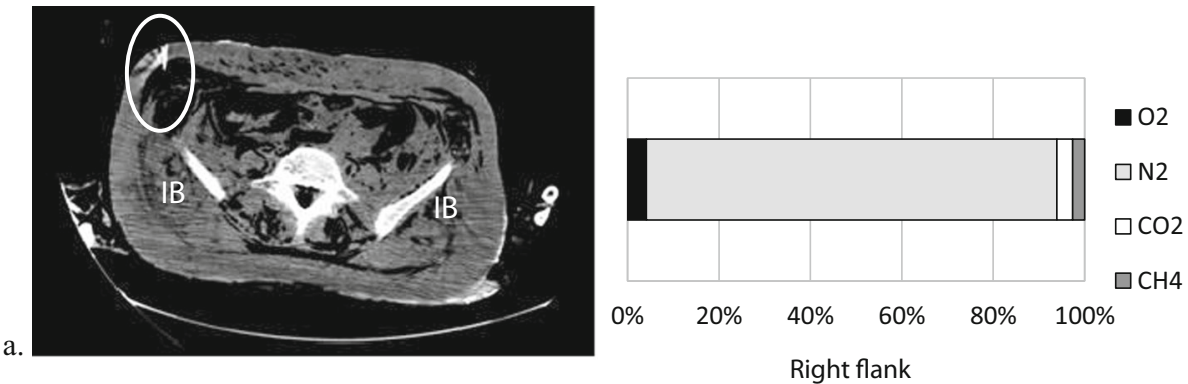

Right flank
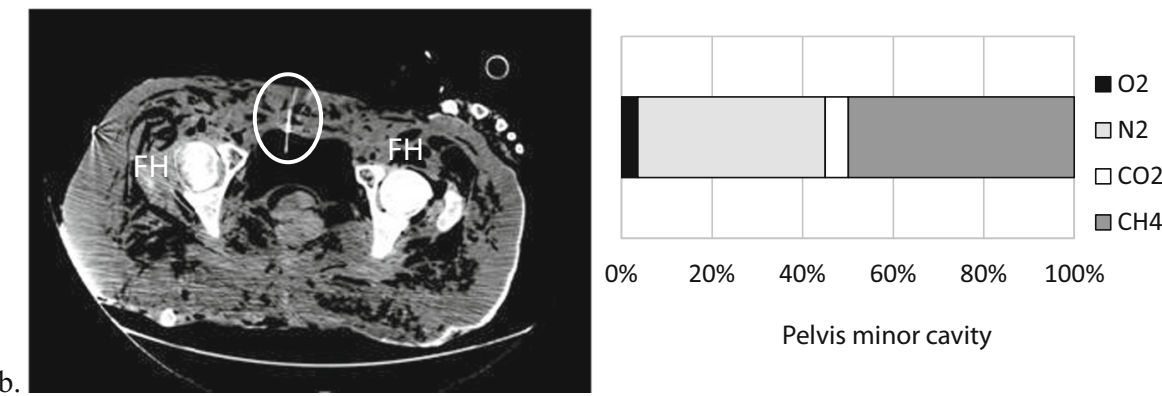

Pelvis minor cavity

$0.7 \%$ of $\mathrm{CH}_{4}$ [15]. Another study reported the cardiac gas composition in bodies exhumed after 10 to 64 weeks $[11,12]$. The composition is very random but a global trend can be noticed. In bodies with a postmortem delay of less than about 30 35 weeks, the concentrations of alteration gases $\mathrm{CO}_{2}$ and $\mathrm{H}_{2}$ are close to or superior to $20 \%$. If the postmortem delay overcomes 35 weeks, $\mathrm{CO}_{2}$ and $\mathrm{H}_{2}$ concentrations tend to decrease and $\mathrm{CH}_{4}$ is generated. Therefore, at the first steps of alteration, $\mathrm{O}_{2}$ and $\mathrm{N}_{2}$ seem to decrease, consumed by the microorganisms which produce $\mathrm{H}_{2}$ and $\mathrm{CO}_{2}$ as fermentation
Fig. 4 CT scan images and gas composition of thoracic and abdominal cavities from a 30 -year buried human body (sampling needles in the white circles on CT scan images; $S$ sternum, $L$ liver). a Thoracic cavity. b Abdominal cavity
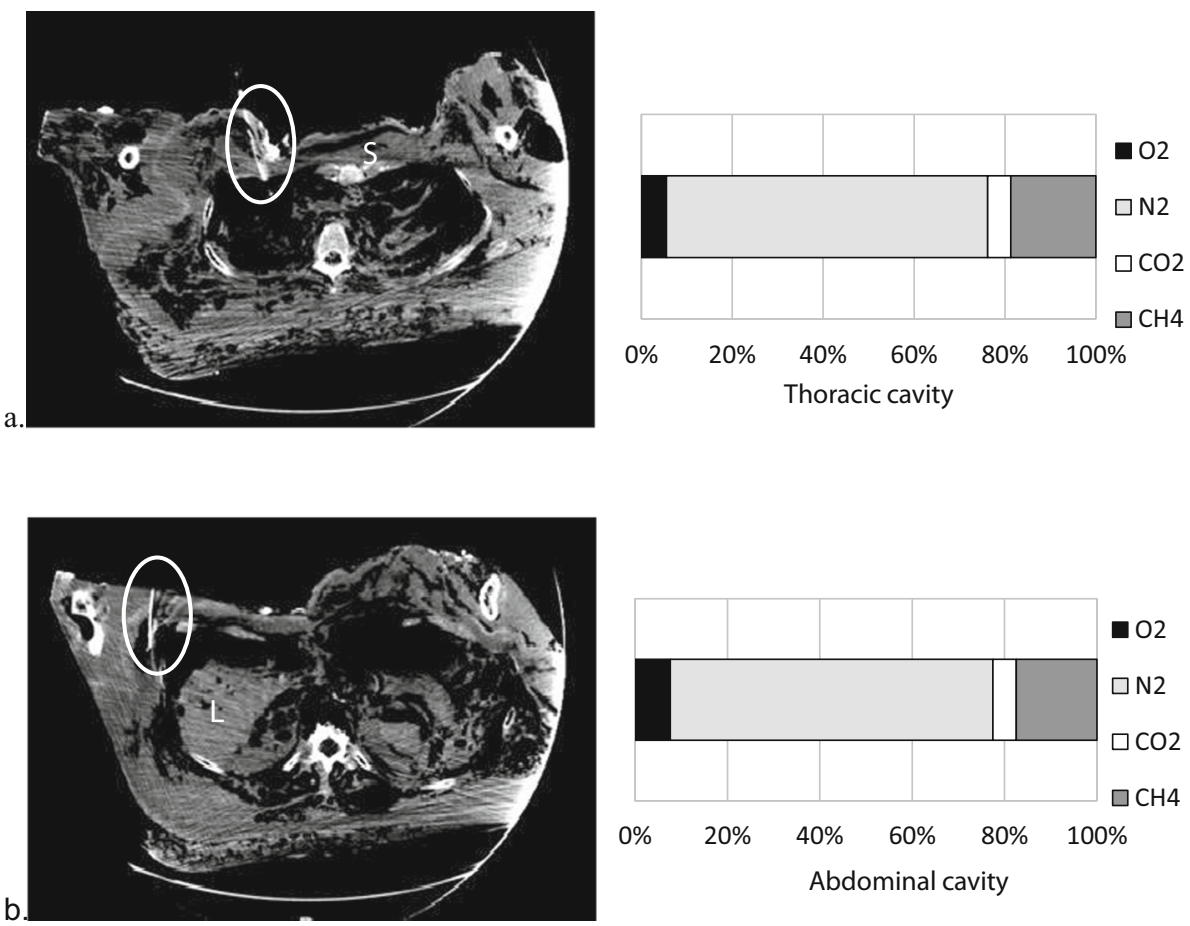
products. After a long time of alteration (several weeks to 1 year), $\mathrm{H}_{2}$ and $\mathrm{CO}_{2}$ decrease and $\mathrm{CH}_{4}$ appears. Indeed, all $\mathrm{CH}_{4}$ bacteria can obtain the energy required for growth by the anaerobic oxidation of molecular $\mathrm{H}_{2}$ with $\mathrm{CO}_{2}$ [15]. However, even if after this kind of postmortem delay (several weeks to 1 year), $\mathrm{CH}_{4}$ concentration reaches a maximum $<10 \%$.

For both cases of this study, only four gases are noticeable: $\mathrm{O}_{2}, \mathrm{~N}_{2}, \mathrm{CO}_{2}$ and $\mathrm{CH}_{4}$. Among all the gas samples, $\mathrm{O}_{2}$ concentration does not overcome $5 \%$. Body 1 presents a high amount of $\mathrm{N}_{2}$ in the right flank (about $90 \%$ ) and small amounts of $\mathrm{CO}_{2}$ and $\mathrm{CH}_{4}$ (both $<5 \%$ ) (Fig. 3a). The important $\mathrm{N}_{2}$ amount could be due to gas diffusion inside the body or air contamination due to the difficulty of sampling (but $\mathrm{O}_{2}$ concentration does not seem to be influenced). However, for the same body, $\mathrm{N}_{2}$ concentration in the pelvic cavity is close to $40 \% . \mathrm{CO}_{2}$ concentration remains similar to this of the right flank $(<5 \%)$ but $\mathrm{CH}_{4}$ concentration represents almost $50 \%$ (Fig. 3b). Gas compositions in the abdominal (Fig. 4a) and thoracic cavities (Fig. 4b) of the body 2 are nearly similar: $\mathrm{O}_{2}$ between 5 and $10 \%, \mathrm{~N}_{2}$ close to $70 \%, \mathrm{CO}_{2}<5 \%$ and $\mathrm{CH}_{4}$ close to $20 \%$.

$\mathrm{H}_{2}$ was surprisingly not present whereas it constitutes a major alteration gas. After 30 years, $\mathrm{H}_{2}$, which is a very volatile gas, could have been released in the ground but the most credible explanation is its anaerobic oxidation with $\mathrm{CO}_{2}$. As for $\mathrm{H}_{2}$, it is surprising to notice the weak amount of $\mathrm{CO}_{2}$. The absence of $\mathrm{H}_{2}$ and the weak amounts of $\mathrm{CO}_{2}(<5 \%$ whatever the body and the sampling site) strengthen the hypothesis of $\mathrm{CH}_{4}$ generation from $\mathrm{H}_{2}$ oxidation by methanogenic bacteria.

In microbiology, $\mathrm{H}_{2}$ and $\mathrm{CO}_{2}$ are major end products of mixed acid fermentation performed by many enteric bacteria including Escherichia, Shigella, Proteus and Yersinia. Sugars can be rapidly transformed in pyruvic acid, latter converted in formic acid produced by pyruvate cleavage. Finally, formic acid is converted in $\mathrm{H}_{2}$ and $\mathrm{CO}_{2}$. Other microorganisms such as anaerobic spore-forming bacteria Clostridium are implied in a fermentation leading to acetic and butyric acids, $\mathrm{H}_{2}$ and $\mathrm{CO}_{2}$. Cleavage of pyruvate yields acetyl-S-CoA, $\mathrm{H}_{2}$ and $\mathrm{CO}_{2}$ directly [15]. As result, $\mathrm{CO}_{2}$ and $\mathrm{H}_{2}$ appear as predominant alteration gases and reliable alteration indicators. However, in the cases herein, $\mathrm{CO}_{2}$ is at weak level and $\mathrm{H}_{2}$ is absent. This observation is explained by the anaerobic oxidation of $\mathrm{H}_{2}$ with $\mathrm{CO}_{2}: 4 \mathrm{H}_{2}+\mathrm{CO}_{2} \rightarrow \mathrm{CH}_{4}+2 \mathrm{H}_{2} \mathrm{O}$. Taking into account the stoichiometry, $\mathrm{H}_{2}$ amount should decrease in larger quantity than $\mathrm{CO}_{2}$. Therefore, it can be hypothesized that all $\mathrm{H}_{2}$ produced during decomposition was converted in $\mathrm{CH}_{4}, \mathrm{H}_{2}$ being the constraining factor. Adipoceres and cold environmental temperatures induce an acidic environment and should limit the growth of anaerobic microflora of normal alteration. Conversely, methanogenic bacteria can growth in various $\mathrm{pH}$ environments and from temperature as cold as $4{ }^{\circ} \mathrm{C}$ (optimum at $22{ }^{\circ} \mathrm{C}$ ) [20]. With high concentration of $\mathrm{CO}_{2}$ and $\mathrm{H}_{2}$, cold temperature and acidified $\mathrm{pH}$, methanogenic activity is ideal.
As a result, the detection of methane in gas sample is a reliable indicator of advanced stage of alteration. The magnitude of the alteration could be directly linked to high concentrations of methane and weak concentrations of $\mathrm{CO}_{2}$ and $\mathrm{H}_{2}$. However, the moisture and environmental temperature seem to be key elements to rule the anaerobic oxidation of $\mathrm{H}_{2}$ in presence of $\mathrm{CO}_{2}$.

The cases presented in this study constitute a specific decomposition because the alteration conditions are optimal for methanogenic microorganisms. For bodies stored in water or in dry atmosphere, the gas composition could change, even in case of long alteration. Low methane amounts could be expected because of the predation which can alter the integrity of the sampling sites leading to leaks of gaseous substrates and air contamination. The use of MDCT guarantees sampling precision even in small gaseous volumes and to find out precise diagnoses when correlated with gas analyses. Additionally, to parameters such as the species, environmental temperature, sampling sites etc., the main source of variations between the studies available originates from the sampling. Underwater direct sampling, airtight syringes, during autopsy (risk of leaks or air contamination), use of aspirometer, CT scan assistance etc., constitute important criteria that need to be harmonized. The body gas sampling protocol developed in our medicolegal centre increases the precision of the sampling and could be extended to other medicolegal centres to compare obtained results.

\section{References}

1. Bernaldo de Quiros Y, Gonzalez-Diaz O, Saavedra P, Arbelo M, Sierra E, Sacchini S, Jepson PD, Mazzariol S, Di Guardo G, Fernandez A (2011) Methodology for in situ gas sampling, transport and laboratory analysis of gases from stranded cetaceans. Sci Rep 1(193):1-10. doi:10.1038/srep00193

2. Musshoff F, Hagemeier L, Kirschbaum K, Madea B (2012) Two cases of suicide by asphyxiation due to helium and argon. Forensic Sci Int 223:e27-e30

3. Auwaerter V, Perdekamp MG, Kempf J, Schmidt U, Weinmann W, Pollak S (2007) Toxicological analysis after asphyxia suicide with helium and a plastic bag. Forensic Sci Int 170:139-141

4. Auwaerter V, Pragst F, Strauch H (2004) Analytical investigations in a death case by suffocation in an argon atmosphere. Forensic Sci Int 143:169-175

5. Varlet V, Augsburger M (2013) Confirmation of natural gas explosion from methane quantification by headspace gas chromatographymass spectrometry (HS-GC-MS) in post-mortem samples: a case report. Int J Legal Med 127(2):413-418

6. Varlet V, Smith F, De Froidmont S, Dominguez A, Rinaldi A, Augsburger M, Mangin P, Grabbherr S (2013) Innovative method for carbon dioxide determination in human postmortem cardiac gas samples using headspace-gas chromatography-mass spectrometry and stable labeled isotope as internal standard. Anal Chem Acta 784:42-46 
7. Levy AD, Harcke HT, Mallak CT (2010) Postmortem imaging MDCT features of postmortem change and decomposition. Am J Forensic Med Pathol 31(1):12-17

8. Thali MJ, Yen K, Schweitzer W, Vock P, Ozdoba C, Dirnhofer R (2003) Into the decomposed body - forensic digital autopsy using multi-slice computed tomography. Forensic Sci Int 134:109-114

9. Jackowski C, Sonnenschein M, Thali MJ, Aghayev E, Yen K, Dirnhofer R, Vock P (2007) Intrahepatic gas at post-mortem computed tomography: forensic experience as a potential guide for in vivo trauma imaging. J Trauma 62(4):979-988

10. Egger C, Bize P, Vaucher P, Mosimann P, Schneider B, Dominguez A, Meuli R, Mangin P, Grabherr S (2012) Distribution of artifactual gas on post-mortem multidetector computed tomography (MDCT). Int J Legal Med 126(1):3-12

11. Bajanowski T, Köhler H, DuChesne A, Koops E, Brinkmann B (1998) Proof of air embolism after exhumation. Int J Legal Med 112:2-7

12. Bajanowski T, West A, Brinkmann B (1998) Proof of fatal air embolism. Int J Legal Med 111:208-211

13. Pierucci G, Gherson G (1968) Studio sperimentale sull'embolia gassosa con particolare riguardo alla differenziazione fra gas embolic e gas putrefattivo. Zacchia 43:347-373, In Italian
14. Bernaldo de Quiros Y, Gonzalez-Diaz O, Mollerlokken A, Brubakk AO, Hjelde A, Saavedra P, Fernandez A (2013) Differentiation at autopsy between in vivo gas embolism and alteration using gas composition analysis. Int J Legal Med 127(2):437-445

15. Sakata M, Miki A, Kazama H, Morita M, Yasoshima S (1980) Studies on the composition of gases in the post-mortem body: animal experiments and two autopsy cases. Forensic Sci Int 15:19-29

16. de Quiros YB, Gonzalez-Diaz O, Arbelo M, Sierra E, Sacchini S, Fernandez A (2012) Decompression vs. decomposition: distribution, amount, and gas composition of bubbles in stranded mammals. Front Physiol 3:177. doi:10.3389/fphys.2012.00177

17. Pedal I, Moosmayer A, Mallach HJ, Oehmichen M (1987) Luftembolie oder fäulnis ? Gasanalytische befunde und ihre interpretation. Z Rechtsmed 99:151-167 (in German)

18. Lawrence $C$ (1997) Interpretation of gas in diving autopsies. SPUMS J 27(4):228-230

19. Keil W, Bretschneider K, Patzelt D, Behning I, Lignitz E, Matz J (1980) Luftembolie oder fäulnisgas? Zur diagnostik der cardialen luftembolie an der leiche. J Beit Gerichtl Med 38:395-408

20. Garcia JL (1998) Les bactéries méthanogènes. C.R. Acad Agric Fr 84:23-33 (In French) 